\title{
Geographic information system for the accumulation and processing of data on road accidents
}

\author{
Alexander Novikov ${ }^{1}$, Ivan Emelianov ${ }^{2 *}$, Andrey Kolvah², and Alexey Tarasov ${ }^{1}$ \\ ${ }^{1}$ Orel State University named after I. S. Turgenev, 302026, Orel, Russia \\ 2 South-West State University, 305040, Kursk, Russia
}

\begin{abstract}
The number of incidents unaccounted for in-state statistics is determined at $92.5 \%$, and the problems arising as a result of such incidents are listed. The structure and interface of an application developed by the employees of the Southwestern State University, which is a geographic information system for accumulating and processing data on road accidents, is presented. A list of information that must be entered into the application is presented, as well as the ability to sort by the required parameters.
\end{abstract}

\section{Introduction}

Currently, in the preparation of documents on the organization of road traffic, such as an integrated scheme of traffic management (ISTM) and the project of traffic management (PTM), information on road traffic accidents (RTA) is required [1]. Traffic accidents can be accounted for by the internal affairs bodies, vehicle owners, state road authorities, and owners of departmental and private roads [2]. Taking into account the profile, for the preparation of ISTM and PTM, statistical data of the Main Directorate for Road Safety of the Ministry of Internal Affairs of the Russian Federation (abbreviated as GIBDD) are used. State statistical reporting on road traffic accidents includes information only about road accidents in which people died or were injured [2]. The rest of the incidents (with less serious consequences) do not appear anywhere in the state statistics, although they (given their large number) can have a significant impact on the organization and safety of road traffic. If we approach the issue of accounting for road accidents not from the point of view of the severity of the consequences for specific participants in the accident, but the point of view of the impact on the living conditions of the people of the municipality or the region as a whole, unaccounted accidents can be much more important. For example, an accident that has arisen on a road section with a large flow of vehicles creates several problems: the occurrence of congestion on the road due to cars of the participants in the accident, an increase in the concentration of harmful substances in the area of the resulting congestion, the occurrence of a state of irritability and anxiety among drivers, increased consumption fuel, delayed delivery of goods and passengers, the need to move in the opposite lane (to

\footnotetext{
* Corresponding author: yuzgu@yandex.ru
} 
bypass the accident site), etc. [4-10]. Thus, biased statistics (with insufficient data) do not allow improving the organization of traffic and reducing the number of accidents.

\section{Materials and methods}

Consider and compare the statistics of the GIBDD and the Russian Association of Motor Insurers (RAMI). According to the GIBDD, in 2019 there were 164358 road accidents, in which 16981 people. killed and 210,877 people. wounded. According to the RAMI, in 2019, 40.6 million OSAGO agreements were concluded, claims for damages of 2.3 million were declared, and 2.2 million accidents were settled [11]. Consequently, at least 2.2 million accidents were registered on the road and could interfere with the movement of the vehicle. If we calculate the percentage of accidents that are included in the traffic police statistics, from the number for which payments were made by insurance companies, then it will be approximately $7.5 \%$, and $92.5 \%$ of the accidents under consideration are not included in state statistics. Consequently, they are not taken into account in the preparation of documents on the organization of road traffic, based on which, in the future, roads and road infrastructure will be designed and built. Thus, at present, there is a need to create an information system for collecting and storing information about all road accidents [12-14].

Employees of Southwestern State University (SWSU) have developed an application for the accumulation of information about road traffic accidents, which includes a geographic information system (GIS). Fig.1. shows the interface of the main application window.

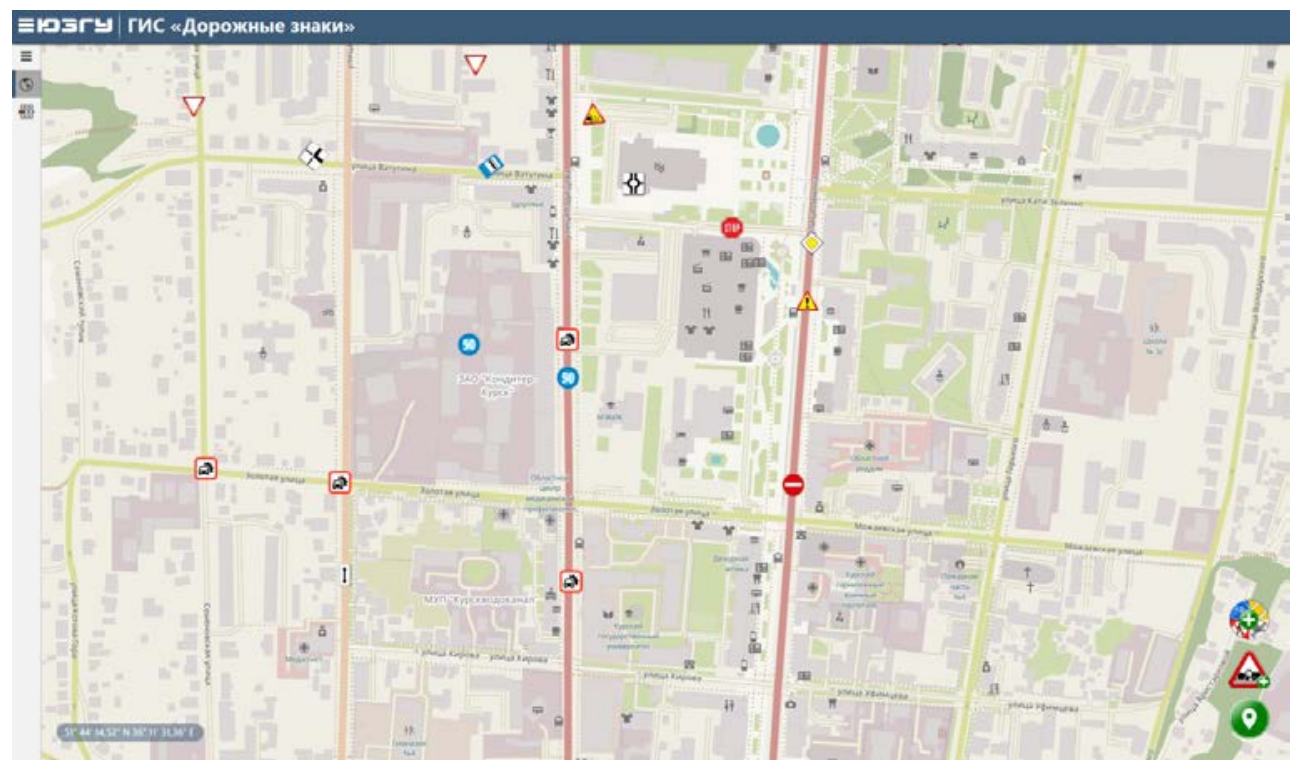

Fig. 1. Interface of the main application window.

The application is designed to collect a huge array of information about road accidents for further detailed analysis. Thanks to this approach, it seems possible to form not only a general picture of road traffic accidents on the map of a city or an entire region but also the subsequent identification of the most dangerous sections of highways or intersections. It is worth noting that in real-time in the application it is also possible to place road signs, both permanent and temporary, which are necessary to indicate the place of road repair work. Fig. 2. shows the road sign selection interface. 


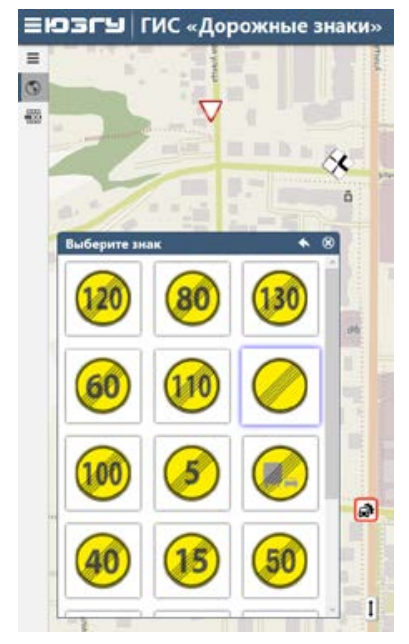

Fig. 2. Interface of the road signs selection window.

The application allows an authorized person, whether it is a traffic police inspector or an emergency commissioner, to enter all the necessary data about an accident directly at the place of its occurrence or at a later time. University specialists have developed a procedure for entering data on road accidents. First, you need to enter the basic information:

1) the place of the accident with the indication of latitude and longitude (determined by the application automatically);

2) the date and time of the incident;

3) possible landmarks of the adjacent territory (to establish the most accurate place);

4) full name of the authorized person (GIBDD inspector);

5) subdivision of the traffic police;

6) the date of completion of the analysis of the accident in the traffic police;

7) the date of completion of the analysis of the accident in court.

Next, you need to enter data about the participants in the accident:

1) type of vehicle (with the ability to choose from the presented list of vehicles);

2) year of issue of the vehicle;

3) the state registration number of the vehicle;

4) full name of the owner and full name of the vehicle driver;

5) the series and number of the driver's license;

6) series and number of the OSAGO policy;

7) the number of people in the vehicle at the time of the accident (with the ability to indicate the injured and the dead);

8) the guilt of the driver.

It should be noted that both the structure and the entered data can be supplemented or changed. The interface of the window for entering data on the road traffic accident participants is shown in Fig. 3. 


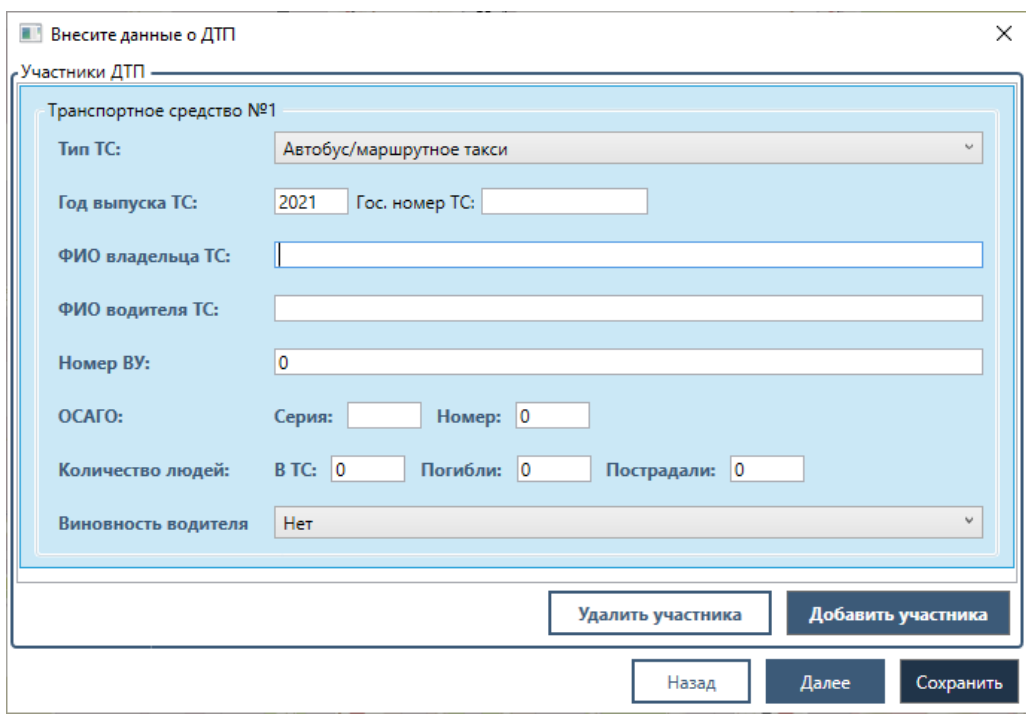

Fig. 3. The interface of the window for entering data on the participants in the accident

After entering the basic data about the accident and about the participants, it is necessary to attach a diagram and photographs from the accident site to the above information (the application allows no more than 10 images). After that, all the entered data is saved in the application. The interface of the data grouping window is shown in Fig. 4.

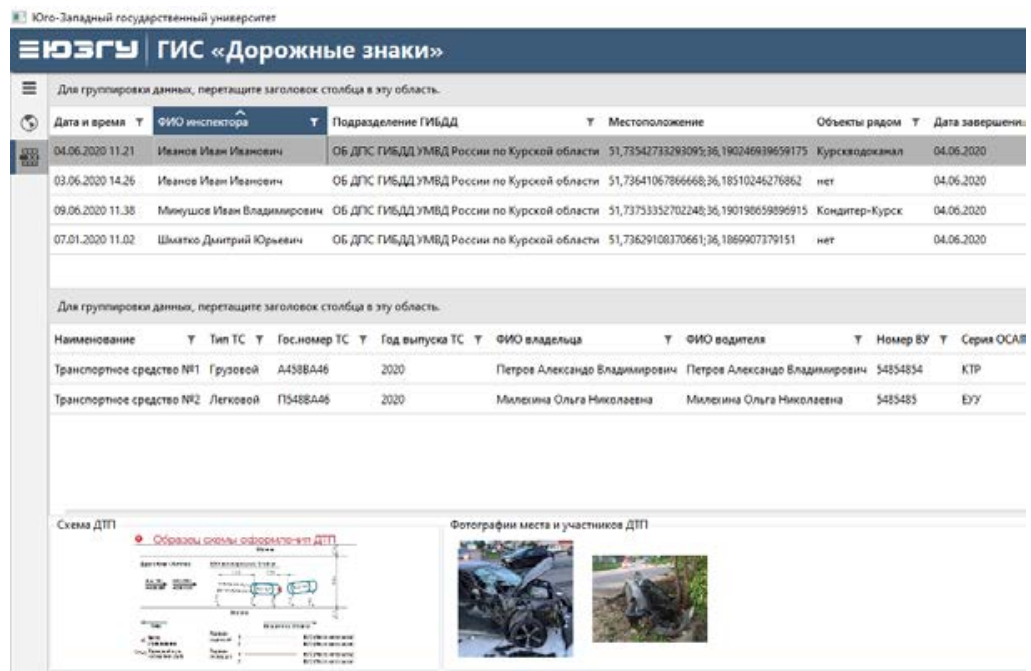

Fig. 4. Interface of the data grouping window

At the moment, all the information about the accident entered into the application is based solely on the data of the GIBDD.

\section{Results and discussion}

An important task is to create conditions for the prompt removal of vehicles of road traffic accidents from the roadway, which is intended to solve the procedure for processing documents on a road traffic accident without the participation of authorized police officers 
[3]. But a more important task is to create such conditions so that as few accidents as possible occur in principle. To solve this problem, it is necessary to identify the causes of all road accidents, which can only be done based on objective and comprehensive statistical data.

Since the developed application stores data on accidents that have occurred, any authorized person has the opportunity at any time to consider in the most detail the necessary case or emergency situation on the road section. For the purpose of a quick and convenient search, the application provides the ability to filter all cases by the required parameter.

For the full-fledged functioning of GIS, only two tasks remain unresolved: how to organize the filling of the system with information about road accidents and which department or organization will perform this function.

\section{Conclusions}

Comparison of the statistical data of the GIBDD and the RAMI showed that the information used for the development of documents on the organization of traffic accounted for only $7.5 \%$ of the total number of accidents, which does not allow us to propose adequate measures to improve traffic capacity and reduce accidents on the road network. In this regard, we can observe the country's road network that does not meet the modern level of motorization, systematic traffic congestion and a high level of accidents. The proposed system will allow to accumulate absolutely all road accidents with a description of the necessary parameters and a mark of the accident site on the map.

\section{References}

1. On approval of the Rules for the preparation of documentation on the organization of road traffic [Text]: Order of the Ministry of Transport of the Russian Federation of June 30, 2020 N 274.

2. On the approval of the Rules for accounting for road traffic accidents, on the amendment and recognition as invalid of some acts of the Government of the Russian Federation [Text]: Resolution of the Government of the Russian Federation of September 19, 2020 N 1502.

3. On compulsory civil liability insurance of vehicle owners (with amendments and additions, entered into force on 03/01/2021) [Text]: Federal Law of April 25, $2002 \mathrm{~N}$ 40-FZ (as amended on 12/08/2020).

4. Jovic Vranes, A., Bjegovic Mikanovic, V., Milin Lazovic, J., Kosanovic, V., Road traffic safety as a public health problem: Evidence from Serbia, Journal of Transport and Health, v. 8 55-62 (2018).

5. Ballay, M., Macurová, L., Kohút, P., Copiak, M., Development of road safety status and the evaluation criterion causes of specific traffic accidents, Transport Means Proceedings of the International Conference, v. 2018-October 765-77022nd (2018).

6. Kolesnikova, D., Karabchuk, T., Salnikova, D., Fattahov, T., Estimation of socioeconomic national losses as a result of road accidents in Russia, Voprosy Ekonomiki, v 2016 131-146 (2016).

7. Tao, L., Zhu, D., Yan, L., Zhang, P., The traffic accident hotspot prediction: Based on the logistic regression method, ICTIS 2015 - 3rd International Conference on Transportation Information and Safety, Proceedings, 107-1103rd (2015). 
8. Mao, L.-Z., Zhang, X.-L., Duan, L.-R., Analysis and research of the social cost of traffic congestion in Beijing, CICTP 2014: Safe, Smart, and Sustainable Multimodal Transportation Systems - Proceedings of the 14th COTA International Conference of Transportation Professionals, 2726-273514th (2014).

9. Wretstrand, A., Holmberg, B., Berntman, M., Safety as a key performance indicator: Creating a safety culture for enhanced passenger safety, comfort, and accessibility, Research in Transportation Economics, v. 48 109-115 (2014).

10. Polyakov A.S., Zhankaziev S.V., Improving the efficiency of the city's transport complex, Science and technology in the road industry No. 4 (78), 3-6 (2016).

11. The Russian Association of Motor Insurers (RAMI) [Electronic resource]: RAMI annual report, 2019 // Access mode: https://autoins.ru/upload/AReport_RSA_2019.pdf

12. Marumo, H., Yokota, M., Development of an automatic detection and alarm system of traffic control for drivers using real-time analysis of pictures on cellular phone handsets, 20th ITS World Congress Tokyo 2013, (2013).

13. Mao, L.-Z., Zhu, H.-G., Duan, L.-R., The social cost of traffic congestion and countermeasures in Beijing, Sustainable Transportation Systems: Plan, Design, Build, Manage, and Maintain - Proceedings of the 9th Asia Pacific Transportation Development Conference, v. x68-769th (2012).

14. Lu, G.-Q., Cheng, B., Lin, Q.-F., Kuzumaki, S., Mei, B.-S., The relationship between accidents and conflicts recorded by drive recorders, FISITA World Automotive Congress 2008, Congress Proceedings - Vehicle Safety, v. 2 52-6032hd (2008). 